\title{
Caring for the elderly
}

\author{
Bert Gordijn $^{1} \cdot$ Henk ten Have ${ }^{2}$
}

Published online: 11 December 2015

(C) Springer Science+Business Media Dordrecht 2015

Sin (2016) explores different consequentialist approaches towards analyzing filial obligations in relation to parents in need of care. Undoubtedly, the question of filial duties is important. It is therefore remarkable that there is relatively little thorough research on this subject in contemporary academic literature. Yet, the analysis of ethical obligations concerning elderly care would be incomplete without a complementary consideration of the ethical responsibilities of the state. There are at least four arguments to support this claim.

\section{Individualism}

Arguably, powerful ideas centering on the individual permeate many aspects of economically developed societies. Never before has there been so much cultural emphasis on self-actualization, education, career, upward mobility, personal development and the like. The focus on the individual easily equals the strength of individualism in renaissance Italy or 17th century Amsterdam. In contrast to previous historical periods though, individualist ideas are today substantially more widespread. In an increasing number of countries, for instance, women are seen as equally entitled as men to enjoy higher education and pursue a career. Similarly differences in ethnicity and social class are less and less regarded as legitimate justi-

Bert Gordijn

bert.gordijn@dcu.ie

Dublin, Ireland

2 Pittsburgh, USA fications for unequal access to a good education. The equalizing influence of the idea of human rights may lie at the basis of these social changes. Be this as it may, historically, the idea that every single member of society, whatever their gender, ethnicity or social class, is entitled to pursue a full suite of avenues of self-actualization is unparalleled. In addition to the many blessings of individualism, however, it has also significantly increased the internalization costs of strong conceptions of filial obligations in terms of long-term care for parents.

\section{Geographic mobility and migration}

People are more mobile than ever before, both within single countries and between different nation states. The reasons are multifarious and complex. Better transport technologies and infrastructure certainly play a role. Also many industries and markets all over the world have liberalized and deregulated during the last few decades. Corporations, NGOs, civil society organizations and academia have increased their geographical radius of action. Mobility for economic and job reasons has increased enormously. Obviously, wars, conflicts and political suppression also cause a good deal of international migration. The global number of international migrants reached 232 million in 2013. The number had risen by over 77 million between 1990 and 2013 (United Nations 2013, 1). This means that, on average, people live farther away from their parents. Gone are the days where it was likely that people lived and died in the same place where they were born. It goes without saying that this has complicated and in many cases made it practically impossible for children to personally care for their parents in any meaningful long-term way. 


\section{Specialized care}

In 2013, according to the Global Health Observatory, the average global life expectancy at birth was 71 years. However, healthy life expectancy was only 62 years (GHO 2016). As life expectancy has risen dramatically over the last century, people have also become more likely to develop various kinds of chronic diseases in the last decade of their life that need specialized medical attention. This means that more and more the care needs of the elderly transgress the limits of the kind of care that can be provided by their children. In many cases more specialized care is needed than children are capable to provide, even if they wished to do so. A good example is palliative care. The Economist Intelligence Unit (2015) in its last Quality of Death Index ranked the state of palliative care across 80 different countries worldwide. It turns out that average income levels seem to be more or less positively correlated with the availability and quality of palliative care. So economically developed countries are ranked as leading, whilst less affluent countries dominate the bottom regions of the list. The UK is at the top, followed by Australia, New Zealand and Ireland. Iraq is at the bottom, followed by Bangladesh, the Philippines and Nigeria (Economist Intelligence Unit 2015, 15). For palliative care to flourish as for many other forms of specialized medical care-it requires serious support of state institutions in terms of education, institutionalization, certification and funding.

\section{Childlessness}

The United Nations' World Fertility Report 2013 states that in low-fertility countries, childlessness among women aged 40-44 years has increased. This was especially the case in Eastern Asia and Europe. In five countries one woman in five had no children by the age of 40-44 years, thus demonstrating a level of childlessness not seen in any country around 1994 (United Nations 2014, viii). It turns out that Singapore had the top level of childlessness with 23\% of women aged 40-44 years (United Nations 2014, 13). Thus, numbers of elderly without children are on the rise. Obviously, these elderly must be cared for.

The argument, then, is that trends in individualism and mobility have significantly increased the internalization costs of filial obligations concerning parents in need of care. Moreover, there are many forms of specialized care, which cannot be provided by parents' children, even if they were willing to do so. In addition, there is an increasing number of elderly without children. For all these reasons, it is imperative to analyze the ethical responsibility of states in taking care of their elderly citizens.

\section{References}

Economist Intelligence Unit. 2015. Quality of Death Index 2015. Ranking palliative care across the world. http://www.econo mistinsights.com/healthcare/analysis/quality-death-index-2015. Accessed on 26 Nov 2015.

GHO. 2016. Global Health Observatory (GHO) data. http://www. who.int/gho/mortality_burden_disease/life_tables/en/. Accessed on 26 Nov 2015.

Sin, W. 2016. Caring for parents: A consequentialist approach. Medicine, Health Care and Philosophy. A European Journal (this issue).

United Nations, Department of Economic and Social Affairs Population Division. 2013. International migration report. http:// www.un.org/en/development/desa/population/publications/migra tion/migration-report-2013.html. Accessed on 26 Nov 2015.

United Nations, Department of Economic and Social Affairs - Population Division. 2014. World fertility report 2013: Fertility at the extremes. http://www.un.org/en/development/desa/population/ theme/fertility/. Accessed on 26 Nov 2015. 